\title{
Ginkgetin, a Biflavone from Ginko biloba Leaves, Inhibits Cyclooxygenases-2 and 5-Lipoxygenase in Mouse Bone Marrow-Derived Mast Cells
}

\author{
Jong Keun Son, ${ }^{a}$ Min Jung Son, ${ }^{a}$ Eunkyung LeE, ${ }^{a}$ Tae Chul Moon, ${ }^{a}$ Kun Ho Son, ${ }^{b}$ Cheorl-Ho KIm, ${ }^{*}, c$ \\ Hyun Pyo KIm, ${ }^{d}$ Sam Sik KAnG,${ }^{e}$ and Hyeun Wook ChANG ${ }^{*, a}$ \\ ${ }^{a}$ College of Pharmacy, Yeungnam University; Gyongsan 712-749, Korea: ${ }^{b}$ Department of Food and Nutrition, Andong \\ National University; Andong 760-749, Korea: ${ }^{c}$ Department of Biochemistry and Molecular Biology, College of Oriental \\ Medicine, Dongguk University and National Research Laboratory for Glycobiology; Kyungju City, Kyungbuk 780-714, \\ Korea: ${ }^{d}$ College of Pharmacy, Kangwon National University; Chunchen 200-701, Korea: and ${ }^{e}$ Naturall Products \\ Research Institute, Seoul National University; Seoul 110-460, Korea. \\ Received August 3, 2005; accepted September 13, 2005
}

\begin{abstract}
Ginkgetin, a biflavone from Ginkgo biloba leaves, was previously reported to be a phospholipase $\mathrm{A}_{2}$ inhibitor and this compound showed the potent antiarthritic activity in rat adjuvant-induced arthritis as well as analgesic activity. This investigation was carried out to find effects on cyclooxygenase-2 (COX-2) in vitro effect. Ginkgetin inhibits COX-2 dependent phases of prostaglandin $\mathrm{D}_{2}\left(\mathrm{PGD}_{2}\right)$ generation in bone marrow-derived mast cells (BMMC) in a concentration-dependent manner with $\mathrm{IC}_{50}$ values of $0.75 \mu \mathrm{M}$. Western blotting probed with specific anti-COX-2 antibodies showed that the decrease in quantity of the PGD 2 product was accompanied by a decrease in the COX-2 protein level. In addition, this compound consistently inhibited the production of leukotriene $\mathrm{C}_{4}\left(\mathrm{LTC}_{4}\right)$ in a dose dependent manner, with an $\mathrm{IC}_{50}$ value of $0.33 \mu \mathrm{M}$. These results demonstrate that ginkgetin has a dual cyclooxygenase-2/5-lipoxygenase inhibitory activity. Furthermore, this compound also inhibited degranulation reaction in a dose dependent manner, with an $\mathrm{IC}_{50}$ value of $6.52 \mu \mathrm{M}$. Therefore, this compound might provide a basis for novel anti-inflammatory agents.
\end{abstract}

Key words Ginkgo biloba; ginkgetin; biflavonoid; cyclooxygenase-2; 5-lipoxygenase; bone marrow-derived mast cell

Flavonoids are widely distributed polyphenol compounds in the plant kingdom. Some flavonoids derivatives were previously reported to possess anti-inflammatory, immunomodulatory activities in vitro and in vivo. ${ }^{1-4)}$ Numerous studies have demonstrated that the anti-inflammatory activity of certain flavonoids might be contributed by inhibiting enzyme activity involved in arachidonic acid cascade related enzymes such as phospholipase $\mathrm{A}_{2}\left(\mathrm{PLA}_{2}\right)$, cyclooxygenase $(\mathrm{COX})$ and lipoxygenases (LOXs). Recently, it was found that some flavonoids suppressed the inducible enzyme expression such as COX-2 $2^{3,5,6)}$ and inducible nitric oxide synthase (iNOS), thereby reducing the production of prostaglandins (PGs) and nitric oxide (NO)., ${ }^{2,-9)}$ Among the flavonoids derivatives, biflavonoids are structurally unique flavonoid-dimmers connected by a $\mathrm{C}-\mathrm{O}-\mathrm{C}$ or $\mathrm{C}-\mathrm{C}$ bond. Previously, we and other groups already reported their biological function in vitro and in vivo. Especially, ochanflavone and several other biflavones were found to be groups IIA secretory phospholipase $\mathrm{A}_{2}$ ( $\mathrm{sPLA}_{2}$-IIA) inhibitor. ${ }^{10,11)}$

Mast cells are one of the most important effector cells in allergic response. When activated, mast cells release a number of biologically active molecules, including histamine, serotonin, proteoglycans and serine proteases through exocytosis, membrane-derived lipid mediators, such as eicosanoids, through the activation of the COX and 5-LOX pathways; and preformed and de novo synthesized various cytokines. ${ }^{12-14)}$ PGs elicit a variety of important biological responses. Among these properties are their ability to induce pain, fever and the symptoms associated with inflammatory responses. Nonsteroidal anti-inflammatory drugs (NSAIDs) reduce the pain and inflammatory swelling by blocking PGs synthesis at the COX stage. However, most NSAIDs which have been used clinically inhibit the production of the PGs that are not only associated with the inflammatory processes but are also involved in maintaining the normal physiological processes. The main limitation in using NSAIDs is their side effects, including gastrointestinal ulcerogenic activity and kidney dysfunction, which limits their therapeutic value of their safe and long-term use. ${ }^{15,16)}$ The enzyme responsible for PGs synthesis exists as two isoforms, COX-1 (constitutive isoform) and COX-2 (inducible form). ${ }^{17,18)}$ Arachidonic acid can also be converted to leukotrienes (LTs) by the action of 5-LOX. Therefore, the development of dual inhibitors that can simultaneously inhibit COX-2/5-LOX and degranulation reaction might enhance their individual anti-inflammatory effects and reduce the undesirable side effects that are associated with NSAIDs. This study describes for the first time a new biological function of ginkgetin for arachidonic cascade metabolism enzymes and degranulation reaction in mast cells.

\section{MATERIALS AND METHODS}

Materials Ginkgetin was isolated from leaves of Ginkgo biloba L. (Ginkgoaceae) and identified according to the previously described method. ${ }^{19)}$ Ginkgetin was dissolved in dimethyl sulfoxide (DMSO) and final concentrations of DMSO were adjusted to $0.1 \%(\mathrm{v} / \mathrm{v})$ in culture media. Control with DMSO alone was run in all cases.

Preparation and Activation of Bone Marrow-Derived Mast Cells (BMMC) and PGD, Determination Bone marrow cells from male Balb/cJ mice were cultured for up to 10 weeks in $50 \%$ enriched medium (RPMI 1640 containing $2 \mathrm{~mm}$ L-glutamine, $0.1 \mathrm{~mm}$ nonessential amino acids, antibi- 
<smiles>COc1cc(O)c2c(=O)cc(-c3ccc(OC)c(-c4c(O)cc(O)c5c(=O)cc(-c6ccc(O)cc6)oc45)c3)oc2c1</smiles>

Fig. 1. Chemical Structure of Ginkgetin

otics and $10 \%$ fetal calf serum) and 50\% WEHI- 3 cell conditioned medium as a source of interleukin (IL)-3. After 3 weeks $>98 \%$ of the cells were found to be BMMC when checked by the previously described procedure. ${ }^{20)}$ To measure inhibitory activity on COX-2 by ginkgetin, cells suspended at a cell density of $5 \times 10^{5}$ cells $/ \mathrm{ml}$ in enriched medium were preincubated with aspirin $(10 \mu \mathrm{g} / \mathrm{ml})$ for $2 \mathrm{~h}$ to irreversibly inactivate preexisting COX-1. After washing, BMMC were activated with $\mathrm{KL}(100 \mathrm{ng} / \mathrm{ml}), \mathrm{IL}-10(100$ $\mathrm{U} / \mathrm{ml})$ and LPS $(100 \mathrm{ng} / \mathrm{ml})$ at $37^{\circ} \mathrm{C}$ for $8 \mathrm{~h}$ in the presence or absence of ginkgetin previously dissolved in dimethylsulfoxide (DMSO). All reactions were stopped by centrifugation at $120 \times \boldsymbol{g}$ at $4{ }^{\circ} \mathrm{C}$ for $5 \mathrm{~min}$. The supernatant and cell pellets were immediately frozen in liquid $\mathrm{N}_{2}$ and stored at $-80^{\circ} \mathrm{C}$ for further analysis. $\mathrm{PGD}_{2}$ was determined using an enzyme immunoassay kit (Cayman Chemical, Ann Arbor, MI, U.S.A.) according to the manufacturer's instruction. Under the conditions employed, COX-2-dependent phases of $\mathrm{PGD}_{2}$ generation reached $1.6 \mathrm{ng} / 10^{6}$ cells. All data was the arithmetic mean of triplicate determinations.

LTC $_{4}$ Determination BMMC suspended in enriched medium at a cell density of $1 \times 10^{6} \mathrm{cells} / \mathrm{ml}$ were pretreated with ginkgetin for $30 \mathrm{~min}$ at $37^{\circ} \mathrm{C}$ and stimulated with $\mathrm{KL}$ $(100 \mathrm{ng} / \mathrm{ml})$. After $20 \mathrm{~min}$ of stimulation, the supernatants were isolated for further analysis by EIA. LTC $_{4}$ was determined using an enzyme immunoassay kit (Cayman Chemical, Ann Arbor, MI, U.S.A.) according to the manufacturer's instruction. Under the conditions employed, 5-LOX dependent $\mathrm{LTC}_{4}$ reached approximately $350 \mathrm{pg} / 10^{6}$ cells. All data was the arithmetic mean of triplicate determinations.

Assay of $\boldsymbol{\beta}$-Hexosaminidase Release $\beta$-Hexosaminidase ( $\beta$-HEX), a marker of mast cell degranulation was quantitated by spectrophotometric analysis of the hydrolysis of $p$ nitrophenyl-2-acetamido-2-deoxy- $\beta$-D-glucopyranoside (Sigma Chemical Co.). Briefly, after harvesting supernatant, cells were lysed in the same volume of medium by freeze and thaw three times. $10 \mathrm{ml}$ of the BMMC lysate or supernatant samples were mixed with $50 \mu \mathrm{l}$ of $\beta$-HEX substrate solution $(1.3 \mathrm{mg} / \mathrm{ml} p$-nitrophenyl-2-acetamido-2-deoxy- $\beta$-D-glucopyranoside in $100 \mathrm{~mm}$ sodium citrate, $\mathrm{pH} 4.5$ ) in each well of 96-well plates and then incubated at $37^{\circ} \mathrm{C}$ for $60 \mathrm{~min}$. The reaction was stopped by adding $140 \mu \mathrm{l}$ of $0.2 \mathrm{M}$ Glycin$\mathrm{NaOH}(\mathrm{pH}$ 10.7). The absorbance at $410 \mathrm{~nm}$ was measured in a microplate reader. The percentage of $\beta$-HEX released into the supernatant was calculated by the following formula: $[\mathrm{S} /(\mathrm{S}+\mathrm{P})] \times 100$, where $\mathrm{S}$ and $\mathrm{P}$ are the $\beta$-HEX contents of supernatant and cell pellet.
SDS-PAGE/Immunoblot Analysis After activation with KL, IL-10 and LPS, BMMC were washed once with $10 \mathrm{~mm}$ phosphate buffer ( $\mathrm{pH}$ 7.4) containing $150 \mathrm{~mm} \mathrm{NaCl}$ (PBS) and lysed in PBS containing $0.1 \%$ SDS and $10 \mathrm{~mm} \beta$-mercaptoethanol at $1 \times 10^{7}$ cells $/ \mathrm{ml}$. The lysate $\left(1 \times 10^{5}\right.$ cells equivalent) was applied to $10 \%$ SDS-polyacrylamide gels. After running the gel, the protein bands were blotted onto nitrocellulose membranes (Schleicher and Schull, Dassel, Germany) using a semi-dry blotter (MilliBlot-SDE system, Millipore, Bedford, MA, U.S.A.) according to the manufacturer's instructions. Membranes were then washed once with $10 \mathrm{~mm}$ Tris-buffered saline (TBS, $\mathrm{pH}$ 7.2) containing $0.1 \%$ tween- 20 (TBS-T), and then blocked for $1 \mathrm{~h}$ in TBS-T containing 3\% skim milk. After washing the membranes with TBS-T, an antibody directed against COX-2 was added at a dilution of $1: 3000-5000$ in TBS-T. After incubation for $2 \mathrm{~h}$ followed by washing three times, membranes were treated for $1 \mathrm{~h}$ with horseradish peroxide-conjugated goat anti-rabbit $\operatorname{IgG}$ (Zymed, South San Francisco, CA, U.S.A.) (diluted to $1: 7000)$ in TBS-T. The protein bands were visualized using an enhanced chemiluminesence (ECL) system (Amersham Corp., Newark, NJ, U.S.A.).

\section{RESULTS AND DISCUSSION}

Biflavonoids such as ochnaflavone, amentoflavone and ginkgetin were found to be inhibitors of group $\mathrm{SPLA}_{2}$ from rat platelet, ${ }^{10)}$ and similar data results were also obtained with morelloflavone. ${ }^{11)}$ In addition, ginkgetin and its isomer isoginkgetin, inhibited the release of archidonic acid metabolites from rat peritoneal macrophages stimulated by phorbol ester or calcium ionophore, $\mathrm{A}_{23187}{ }^{21)}$ and also inhibited lymphocyte proliferation induced by T- or B-cell mitogen. ${ }^{1)}$ Furthermore, previously we also reported that gingketin and bilobetin inhibited tumor necrosis factor- $\alpha$ (TNF- $\alpha$ ) production and COX-2 as well as iNOS protein expression in Raw264.7 cell line. ${ }^{3)}$ Taken together, data from the above studies strongly suggest that ginkgetin may affect mast cells activation.

Murakami et al. reported that BMMC exhibit biphasic $\mathrm{PGD}_{2}$ biosynthetic responses over time, in addition to COX1-dependent immediate and COX-2-dependent delayed responses. The immediate $\mathrm{PGD}_{2}$ generation occurring within $2 \mathrm{~h}$ is associated with the coupling of COX-1 and the delayed $\mathrm{PGD}_{2}$ generation, which occurs after several hours of culturing (during $2-10 \mathrm{~h}$ ), is associated with the de novo induction and function of COX-2 after stimulation with particular cytokines and LPS combinations. ${ }^{22)}$ This cell model also appears to be suitable for assessing the effect of 5-LOX inhibitors, since the immediate $\mathrm{LTC}_{4}$ generation elicited by the IgE-dependent or cytokine-initiated stimulus occurs in BMMC through 5-LOX. ${ }^{23)}$ Therefore, the BMMC system is useful for screening selective COX-1/COX-2 or 5-LOX and COX-2/5-LOX dual inhibitors from various sources. ${ }^{24,25)}$ When the BMMC were activated with a combination of $\mathrm{KL}$, IL-10 and LPS in the presence or absence of ginkgetin, the COX-2-dependent phase of $\mathrm{PGD}_{2}$ generation was inhibited in a dose-dependent manner with an $\mathrm{IC}_{50}$ value of approximately $0.75 \mu \mathrm{M}$ (Fig. 2A), while in the presence of $10 \mu \mathrm{M}$ of this compound did not inhibited COX-1 dependent phase of $\mathrm{PGD}_{2}$ generation (data not shown). 
(A)

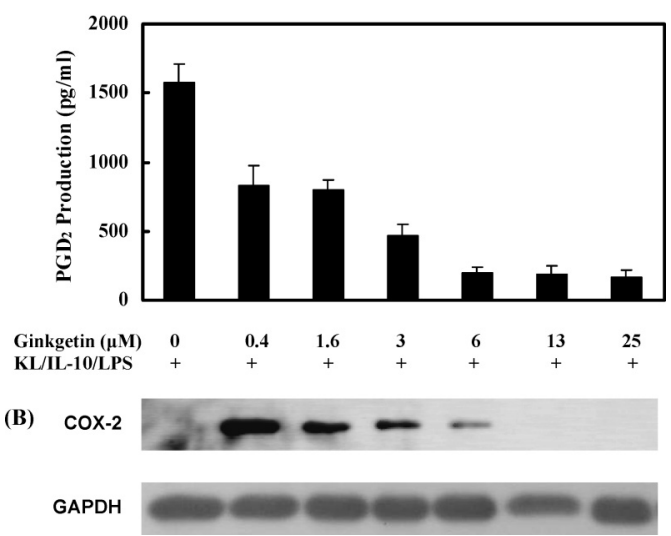

Fig. 2. Effect of Ginkgetin on COX-2 Dependent $\mathrm{PGD}_{2}$ Generation (A) and COX-2 Protein and GAPDH Expression (B)

$\mathrm{BMMC}$ were preincubated for $30 \mathrm{~min}$ with the indicated concentration of ginkgetin and then stimulated with KL $(100 \mathrm{ng} / \mathrm{ml}), \mathrm{IL}-10(100 \mathrm{U} / \mathrm{ml})$ and LPS $(100 \mathrm{ng} / \mathrm{ml})$ at $37^{\circ} \mathrm{C}$ for $8 \mathrm{~h}$ in the presence or absence of ginkgetin. $\mathrm{PGD}_{2}$ released into the supernatant was quantified by EIA kit. Samples were processed by SDS-PAGE and transferred to a nitrocellulose filter. The immunoblot was then probed with anti-COX-2 at a dilution $1: 3000$. The procedure was described in Materials and Methods in detail.

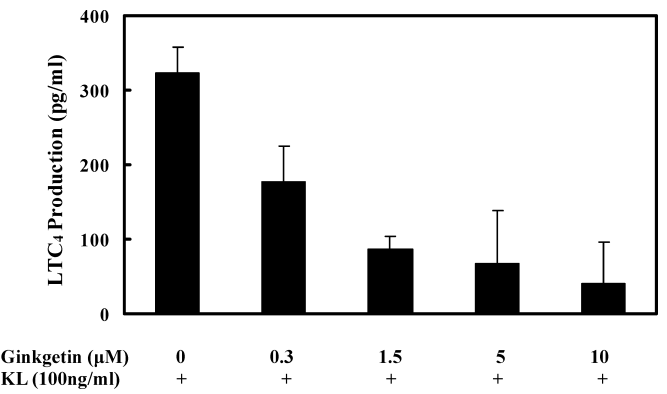

Fig. 3. Effect of Ginkgetin on the Generation of $\mathrm{LTC}_{4}$

BMMC were pre-incubated for $30 \mathrm{~min}$ with the indicated concentrations of ginkgetin and then stimulated with $100 \mathrm{ng} / \mathrm{ml}$ of $\mathrm{KL}$ for $15 \mathrm{~min}$. $\mathrm{LTC}_{4}$ released into the supernatant was quantified by EIA kit. All data was the arithmetic mean of triplicate determinations.

The inhibitory effect of the ginkgetin on $\mathrm{PGD}_{2}$ production was examined to determine if it is a direct effect of the COX2 protein or if this inhibition is mediated by some other mechanism. As shown in Fig. 2B, the COX-2 protein was not detected in unstimulated BMMC, whereas combination of $\mathrm{KL}$, IL-10 and LPS strongly induced the formation of detectable COX-2 protein and COX-2 protein expression was inhibited in a dose-dependent manner by ginkgetin.

Arachidonic acid can also be converted to leukotrienes (LTs) by the action 5-LOX in BMMC. The inhibition of 5LOX is believed to be the ideal treatment for allergic diseases and asthma. ${ }^{26)}$ Therefore, the inhibitory activity of ginkgetin on the generation of $\mathrm{LTC}_{4}$ in the BMMC was examined. Fig. 3 shows that the BMMC stimulated with KL for $15 \mathrm{~min}$ produced approximately $350 \mathrm{pg} / \mathrm{ml} \mathrm{LTC}_{4}$, and preincubation of the BMMC with ginkgetin resulted in the dosedependent suppression of this $\mathrm{LTC}_{4}$ biosynthesis with an $\mathrm{IC}_{50}$ value of $0.33 \mu \mathrm{M}$.

Mast cells are one of the most important effector cells in allergic response. They have long been implicated in the pathology and mortality of anaphylaxis and other allergic

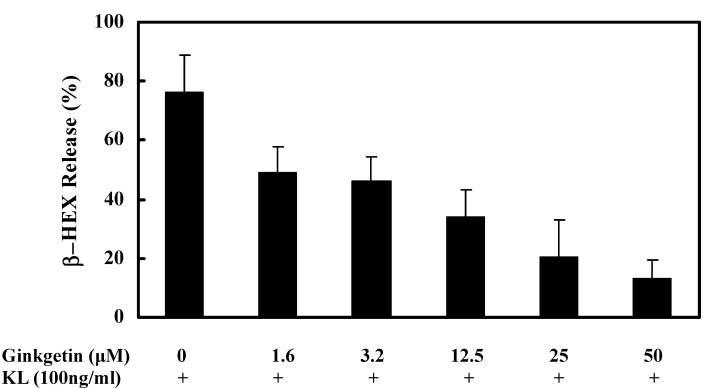

Fig. 4. Effect of Ginkgetin on the Release of $\beta$-Hexosaminidase

BMMC were pre-incubated for $30 \mathrm{~min}$ with the indicated concentrations of ginkgetin and then stimulated with $100 \mathrm{ng} / \mathrm{ml}$ of $\mathrm{KL}$ for $15 \mathrm{~min}$. $\beta$-Hexosaminidase released into the supernatant cell lysate was measured. The procedure was described in Materials and Methods in detail. All data was the arithmetic mean of triplicate determinations.

disorders by virtue of both their ability to be activated through $\mathrm{Fc}_{\varepsilon} \mathrm{RI}$ bound antigen-specific IgE and their concentration at surfaces that interface with the external environment. Mast cells may also be activated by various cytokines through each cytokine receptors. Activation through any of these receptors leads to release of a number of biologically active molecules, including histamine, serotonin, proteoglycans and neutral proteases. Among these molecules, histamine is one of the most important chemical mediators in the pathologic allergic reaction. ${ }^{27)}$ When mast cells are activated by various stimuli, the release of histamine bears a close parallel to that of $\beta$-Hex, which is one of degranulation marker. Therefore, the inhibitory activity of ginkgetin on the degranulation reaction in the BMMC was examined. As shown in Fig. 4, ginkgetin caused the dose-dependent inhibition of $\beta$ Hex release with an $\mathrm{IC}_{50}$ value of $6.52 \mu \mathrm{M}$.

The present study showed that ginkgetin may be a useful biochemical and pharmacological tool for determining the role of COX-2/5-LOX dual inhibitors and/or antihistamine agents in certain physiological and pathological events.

Acknowledgment This work was supported by a Korean Research Foundation Grant (KRF-2004-005-E00003).

\section{REFERENCES}

1) Lee S. J., Choi J. H., Son K. H., Chang H. W., Kang S. S., Kim H. P., Life Sci., 57, 551-558 (1995).

2) Kim H. K., Son K. H., Chang H. W., Kang S. S., Kim H. P., Planta Med., 65, 465-467 (1999).

3) Baek S. H., Yun S. S., Kwon T. K., Kim J. R., Chang H. W., Kwak J. Y., Kim J. H., Kwun K. B., Shock, 12, 473-478 (1999).

4) Kwak W. J., Han C. K., Chang H. W., Kang S. S., Park B. K., Kim H. P., Planta Med., 68, 316-321 (2002).

5) Kim H. P., Mani I., Iversen L., ZibohV. A., Prostaglandins Leukot. Essent. Fatty Acids, 58, 17-24 (1998).

6) McMurray R. W., Hardy K. J., Am. J. Med. Sci., 323, 181-189 (2002).

7) Sadowska-Krowicka H., Mannick E. E., Oliver P. D., Sandoval M., Zhang X. J., Eloby-Childess S., Clark D. A., Miller M. J., Proc. Soc. Exp. Biol. Med., 217, 351-357 (1998).

8) Cheon B. S., Kim Y. H., Son K. S., Chang H. W., Kang S. S., Kim H. P., Planta Med., 66, 596-600 (2000).

9) Kim S. J., Park H., Kim H. P., Arch. Pharm. Res., 27, 937-943 (2004).

10) Chang H. W., Baek S. H., Chung K. W., Son K. H., Kim H. P., Kang S. S., Biochem. Biophys. Res. Commun., 205, 843-849 (1994).

11) Gil B., Sanz M. J., Terencio M. C., Gunasegaran R., Paya M., Alcaraz M. J., Biochem. Pharmacol., 53, 733-740 (1997). 
12) Stevens R. L., Austen K. F., Immunol. Today, 10, 381-386 (1989).

13) Yamaguchi M., Sayama K., Yano K., Lantz C. S., Noben-Trauth N., Ra C., Costa J. J., Galli S. J., J. Immunol., 162, 5455-5465 (1999).

14) Murakami M., Kudo I., Adv. Immunol., 77, 163-194 (2001)

15) Vane J. R., Nature: New Biol., 231, 232-235 (1971).

16) Whittle B. J., Higgs G. A., Eakins K. E., Vane J. R., Nature (London), 284, 271-273 (1980).

17) Maier J. A., Hla T., Maciag T., J. Biol. Chem., 265, 10805-10808 (1990).

18) O’Banion M. K., Winn V. D., Young D. A., Proc. Natl. Acad. Sci. U.S.A., 89, 4888-4892 (1992).

19) Kang S. S., Kim J. S., Kwak W. J., Kim K. H., Kor. J. Pharmacogn., 21, 111-120 (1990).

20) Murakami M., Kambe T., Shimbara S., Kudo I., J. Biol. Chem., 274, 3103-3115 (1999).
21) Lee S. J., Son K. H., Chang H. W., Kang S. S., Kim H. P., Arch. Pharm. Res., 20, 535-538 (1997).

22) Murakami M., Matsumoto R., Austen K. F., Arm J. P., J. Biol. Chem., 269, 22269-22275 (1994).

23) Murakami M., Austen K. F., Arm J. P., J. Exp. Med., 182, 197-206 (1995).

24) Moon T. C., Murakami M., Kudo I., Son K. H., Kim H. P., Kang S. S., Chang H. W., Inflam. Res., 48, 621-625 (1999).

25) Lee S. H., Son M. J., Ju H. K., Lin C. X., Moon T. C., Choi H. G., Son J. K., Chang H. W., Biol. Pharm. Bull., 27, 786-788 (2004).

26) Fiorucci S., Meli R., Bucci M., Cirino G., Biochem. Pharmacol., 62, 1433 - 1438 (2001).

27) Kitamura Y., Arerugi, 54, 45-47 (2005).

28) Kim H. K., Son K. H., Chang H. W., Kang S. S., Kim H. P., Planta Med., 65, 465-467 (1999). 